\title{
Taxionomias toponímicas e relações com a Terminologia
}

\section{Toponymic taxonomies and relations with Terminology}

Renato Rodrigues Pereira ${ }^{1}$

Unesp

astrolabiorrp30@gmail.com

Odair Luiz Nadin

Unesp

odairnadin@fclar.unesp.br

Resumo: Neste artigo, analisam-se as taxionomias toponímicas de Dick (1992) enquanto unidades terminológicas de uma área do conhecimento, dos pontos de vista linguístico (estrutura formal e semântica) e funcional, ambos numa perspectiva descritiva com foco nas seguintes taxes de natureza antropocultural: axiotopônimos e hierotopônimos, como forma de recuperar a essência motivadora de cada uma delas e, com isso, apresentar algumas reflexões e uma proposta de nova taxe que possa dar conta da motivação de alguns topônimos que por vezes não são classificados de forma clara e objetiva. Consideramos as taxionomias como termos da Toponímia. Para tanto, orientamo-nos, sobretudo, pelos princípios teóricos da Teoria Comunicativa da Terminologia (CABRÉ, 1999) e da Toponímia (DICK, 1992).

Palavras-chave: Terminologia; Taxionomias toponímicas; Léxico.

${ }^{1}$ Bolsista de doutorado do CNPq. 
Abstract: In this article, we analyze the toponymic taxonomies of Dick (1992) as terminological units of a field of knowledge, from linguistic (formal and semantic structure) and functional points of view, both under a descriptive perspective, focusing on the following antropocultural taxes: axiotoponymies and hierotopoymies, as a way to recover the motivation essence of each of them and, therefore, present some reflections and a proposal for a new tax that can comprehend the motivation of some toponyms that sometimes are not classified clearly or objectively. We consider taxonomies as terms of Toponymy. For that reason, we are guided especially by theoretical and methodological principles of the Communicative Theory of Terminology (CABRÉ, 1999) and Toponymy (DICK, 1992).

Keywords: Terminology; Toponymical taxonomies; Lexicon.

Recebido em 03 de setembro de 2015. Aprovado 29 de fevereiro de 2016.

\section{Introdução}

Temos, neste texto, o objetivo de apresentar uma análise das taxionomias toponímicas de Dick (1992) enquanto unidades terminológicas (UTs) de uma área de conhecimento. Para isso, fundamentamos as discussões em dois pilares teóricos: a Terminologia (CABRÉ, 1999) e a Toponímia (DICK, 1992).

O primeiro "pilar teórico" que sustenta as discussões aqui apresentadas é, como dito, a Terminologia, sobretudo em sua vertente comunicativa. A Terminologia é uma área do conhecimento em destaque na sociedade moderna principalmente em virtude dos avanços tecnológicos e científicos e da intensificação das comunicações internacionais. Os trabalhos terminológicos têm considerado diversas possibilidades de estudos de unidades léxicas especializadas (ULE) nas mais diversas áreas das ciências e das técnicas. A partir de uma perspectiva formal, funcional e semântica (CABRÉ, 1999, p. 82), esses trabalhos procuram descrever e analisar o funcionamento de unidades léxicas em uso, como termos de uma dada área, assim como propor, quando necessário e solicitado por órgãos de padronização e normalização (ISO, ABNT etc.), unidades que 
possam ser terminológicas, a depender das necessidades, por exemplo, de denominação de novos conceitos.

Desde a década de 1930, os estudos terminológicos têm passado por transformações que possibilitaram a essa área de conhecimento adquirir o status de ciência, com metodologia e objeto de estudo próprios. Tais estudos tinham como objetivo principal estabelecer um modelo normalizador da Terminologia.

Barros (2004, p. 35-37) descreve as diferentes fases pelas quais passaram os estudos terminológicos até sua consolidação como ciência. Para a autora, de 1930 a 1960, período em que se deu origem aos estudos terminológicos, encontra-se uma ciência de caráter sistemático, de perspectiva prescritiva, em que as terminologias deveriam ser vistas como homogêneas enquanto língua de especialidade, não fazendo parte da língua natural ou geral. É nesse contexto que surge, então, a Teoria Geral da Terminologia (TGT), a partir da tese de doutorado de Eugen Bernhard Casper Wüster. Ainda segundo Barros, os anos seguintes 1960-1975 - caracterizaram-se como o período de desenvolvimento dessa área, sobretudo em virtude do advento da informática, promovendo, entre outras coisas, o surgimento dos primeiros bancos de dados terminológicos mono, bi ou multilíngues. Nessa fase, a "terminologia adquire dimensões internacionais e a abordagem normativa das línguas e das terminologias desenvolve-se de modo expressivo" (BARROS, 2004, p. 35).

Ainda segundo a autora, nos anos seguintes, especialmente até meados dos anos 1980, houve questões relacionadas a planejamentos linguísticos e popularização da informática que contribuíram para o fortalecimento da Terminologia enquanto ciência e de sua expansão territorial.

Nas décadas de 1980 e 1990, no entanto, muitos pesquisadores (Gaudin, Gambier, Cabré, Temmerman, entre outros) começaram a questionar alguns pressupostos da TGT e se dedicaram à análise dessa teoria a fim de propor novos caminhos para os estudos terminológicos (SILVA, 2008, p. 70). Para o autor, esses pesquisadores rechaçaram a posição prescritiva da Terminologia defendida até então e, a partir de pontos de vista mais linguísticos, propuseram outras alternativas de carácter descritivo para os estudos terminológicos, sob enfoques variacionistas, comunicativos e cognitivos. Surgem, assim, diferentes teorias, como a Socioterminologia, a Teoria Comunicativa da Terminologia (TCT) e a Teoria Sociocognitiva da Terminologia. 
O segundo "pilar teórico", a Toponímia, por sua vez, tem como objetivo analisar os nomes de lugares em geral, levando em consideração aspectos linguísticos e extralinguísticos. Para este último aspecto, faz-se necessário recorrer a outras áreas do conhecimento, como a História, a Geografia, a Antropologia e a Dialetologia, por exemplo, com a intenção de descobrir a motivação dos topônimos. Nesse contexto, Maria Vicentina de Paula do Amaral Dick, toponimista brasileira que desde 1980 tem se debruçado em pesquisas relacionadas aos nomes de lugares, propôs um modelo de taxionomias toponímicas que pudesse, por meio da análise da estrutura formal do topônimo, evidenciar sua motivação. Essas taxes têm orientado os estudos da Toponímia no Brasil, pois foram concebidas com base na realidade brasileira, conforme Isquerdo (1996, p. 115).

Por se tratar de uma terminologia da Toponímia, propomo-nos a analisar o modelo taxionômico de classificação dos topônimos de Dick (1992) à luz dos princípios teórico-terminológicos da TCT, sobretudo no tocante à análise funcional, formal e semântica das UTs (CABRÉ, 1999, p. 82). Inicialmente, teceremos algumas considerações sobre Terminologia, com especial atenção aos princípios da TCT e, em seguida, apresentaremos as taxionomias de Dick (1992) para, então, desenvolver nossa análise e discussão sobre os axiotopônimos e os hierotopônimos e desenvolver uma proposta de classificação taxionômica.

\section{Terminologia: definição e abordagens}

Muitos foram os motivos que levaram o homem a criar termos. Os primeiros surgiram da necessidade de nomear objetos e situações de áreas, como a Agricultura, o Comércio, a Medicina e a Botânica.

Com a Revolução Industrial europeia nos séculos XVIII e XIX, transformações radicais impuseram à comunidade uma situação de mudança de postura ante a necessidade de comunicações inequívocas devido ao grande número de novas máquinas, atividades diferentes daquelas de subsistência que até então existiam e meio de comunicação impresso que carecia de uma linguagem até certo ponto mais homogênea para que as comunicações sobre o novo não se tornassem ambíguas e equivocadas.

Devido a essas mudanças socioeconônicas e também políticas, novos termos foram criados. De acordo com Barros (2004, p. 26), "a cada nova invenção, a cada nova situação, atividade, produto, serviço, reivindicação, lei etc., surgiram novos termos correspondentes". Essa 
necessidade linguística imposta pelos acontecimentos históricos daquele momento gerou, consequentemente, novas exigências de comunicação, sobretudo escrita, tornando inevitável a constituição de uma "língua padrão" que, segundo Corbeil (1984, apud Barros, 2004, p. 27), conduziu

a um importante trabalho de descrição linguística, de codificação da língua, de normalização das terminologias, de elaboração e de difusão de obras de referência em forma de gramática, de dicionários, de léxicos ou de manuais de todo tipo, desde manuais de pronúncia até manuais de dificuldades ortográficas.

Nesse contexto, surgem na Europa os primeiros trabalhos que estabeleceram a Terminologia como uma disciplina, cujos principais estudiosos foram Lotte (1889-1950), da Escola Soviética de Terminologia, e o engenheiro austríaco Wüster (1898-1977), fundador da Escola de Viena. Estudos sobre as origens e o desenvolvimento da Terminologia como ciência evidenciam que esses autores são os precursores da disciplina. Entretanto, foi a partir da tese de doutorado de Wüster, intitulada A normalização internacional da terminologia (1931), que se apresenta a sistematização de dada terminologia. Seu trabalho deu origem, mais tarde, à TGT.

A TGT tem como uma de suas principais características "a atenção da disciplina nos conceitos, e orienta os trabalhos terminológicos para a normalização de termos e noções" (CABRÉ, 1999, p. 73). A abordagem prescritiva de Wüster desconsidera questões de sinonímia, homonímia, polissemia ou qualquer tipo de variação para assegurar a univocidade da comunicação profissional. Essa visão prescritiva da TGT foi um dos pontos mais questionados nos anos 1990.

Podemos apresentar de forma resumida as características fundamentais da TGT em oito pontos expostos por Cabré (1999, p. 111) quando assinala que: i) a terminologia é concebida como uma "matéria autônoma" e se defende como um "campo de intersecção" constituído pelas "ciências das coisas", e por outras disciplinas como a "linguística", a "lógica", a "ontologia" e a "informática"; ii) a teoria tem como objeto de estudo os termos técnico-científicos, entendidos como unidades específicas de um âmbito de especialidade, de uso circunscrito a este âmbito; iii) os termos se definem como unidades semióticas compostas 
de conceito e denominação, cuja identidade só se justifica em um campo de especialidade; iv) os termos são analisados a partir do conceito que representam e, por isso, assume-se que o conceito precede a denominação. Essa é a característica que justifica a orientação onomasiológica dos estudos da TGT; v) os conceitos de um mesmo âmbito especializado mantém entre si relações de diferentes tipos. O conjunto destas relações entre os conceitos constitui a "estrutura conceitual" de uma matéria; vi) o valor de um termo se estabelece pelo lugar que ocupa na estrutura conceitual de uma matéria; vii) o objetivo do estudo dos termos é a normalização conceitual e denominativa, monolíngue, no caso da comunicação profissional nacional, ou plurilíngue, no caso da comunicação internacional; viii) a finalidade aplicada da normalização terminológica é garantir a precisão e univocidade da comunicação estritamente profissional mediante o uso dos termos normalizados.

Em suma, vale ressaltar a importância de Wüster e da TGT para os estudos terminológicos, pois foi a partir dos postulados desse estudioso que a Terminologia se estabeleceu como um campo de investigação autônomo, com fundamentos teórico-metodológicos próprios.

Entretanto, com o desenvolvimento dos estudos terminológicos, pesquisadores começaram a questionar a real funcionalidade dos pressupostos propostos por Wüster, de forma que as investigações na área evidenciaram novos caminhos que poderiam ser seguidos e que considerariam também a comunicação especializada, ao passo que é nela - comunicação - que os termos se realizam (CABRÉ, 1999).

De acordo com Krieger e Finatto (2004, p. 34), "de modo geral, as novas proposições criticam os limites de alcance da TGT que, por seu caráter prescritivo, conduzem ao apagamento dos aspectos comunicativos e pragmáticos que também envolvem o léxico temático".

Da visão proposta por Wüster e seus discípulos, cuja defesa principal centrava-se na normalização e na monorreferencialidade dos termos, à visão sociocognitiva da terminologia proposta por Temmerman (2000), construíram-se postulados que passam pelo uso social da língua, pelas teorias da comunicação e por abordagens cognitivas. Assim, criaram-se novas perspectivas para os estudos terminológicos: a social, a cognitiva e a comunicativa que privilegiam a comunicação em 
detrimento da normalização e propõem enfoques variacionistas, cognitivos e comunicativos para a Terminologia. (SILVA, 2008, p. 70).

Enquanto a TGT considera que os termos de uma determinada área técnica ou científica só pertencem a ela, não sendo permitida variação de nenhum tipo ou grau, por isso a expressão "língua de especialidade" para se referir ao conjunto desses termos em uma dada área, nos estudos posteriores de vertentes variacionistas e comunicativas, como os da TCT, os termos são entendidos como unidades léxicas pertencentes às línguas naturais que se realizam como termos no uso, ou seja, estão numa situação de ressignificação. Assim, questões como variação, sinonímia e homonímia passam a ser também objetos de descrição e análise nos estudos terminológicos contemporâneos.

A TCT, proposta por Cabré (1999), defende, entre outros aspectos, que uma unidade léxica de qualquer língua natural assume valor de termo em decorrência de seu uso em um dado contexto especializado, ou seja, um termo, segundo a autora, a priori não pertence a uma área específica, mas se realiza nessa área.

A TCT tem como princípio a visão linguística sobre a Terminologia, em que o termo é visto como integrante de um determinado âmbito, sem perder as características próprias de qualquer unidade do sistema linguístico das línguas naturais. Nessa linha epistemológica, o termo é considerado um signo linguístico em funcionamento numa situação de comunicação em determinada área de especialidade e, por ser um signo da língua natural, passa por todos os fenômenos pelos quais passa qualquer unidade léxica da língua, entre os quais destacamos a polissemia, a sinonímia, a homonímia e a variação, seja denominativa ou conceitual.

De acordo com Cabré (1999, p. 122-124), um trabalho terminológico que se ocupa das orientações teórico-metodológicas da TCT precisa refletir em sua prática os seguintes pressupostos: i) tratase de um campo interdisciplinar construído com base nos suportes epistemológicos da teoria do conhecimento, da teoria da comunicação e da teoria da linguagem; ii) o objeto de estudo desta teoria são as UTs que fazem parte de uma língua natural e da gramática dessa língua; iii) os termos são unidades léxicas ativadas por suas condições pragmáticas de adequação a um tipo de comunicação, ou seja, ao contexto de 
especialidade; iv) o significado de um termo nunca é absoluto, e sim relativo, segundo cada âmbito e situação de uso, significando que há uma simultaneidade de valores entre denominação e significado, a depender do contexto pragmático; v) os conceitos de uma área de especialidade mantêm relações de diferentes tipos, constituindo a estrutura conceitual de uma especialidade; vi) os termos não pertencem a uma única área de especialidade, uma vez que são usados em áreas específicas com um valor singular. Logo, o valor de um termo se estabelece pelo lugar que ele ocupa na estruturação conceitual de uma área; vii) o objetivo primeiro da Terminologia teórica é descrever as unidades léxicas, levando em consideração os aspectos formais, funcionais e semânticos que caracterizam as unidades léxicas de uma língua natural em termos de uma determinada área de especialidade; viii) em decorrência da dupla função dos termos - a representação do conhecimento especializado e sua transferência, ainda que em graus e modos distintos, assim como situações também diversas -, a compilação e análise das UTs permitem muitas aplicações.

E importante ressaltar que determinadas áreas do conhecimento, como a Toponímia, a Química, a Botânica e a Anatomia, possuem termos muito específicos que dificilmente migrariam (não é impossível que ocorra) para outras áreas ou para o uso comum da língua. Isso, no entanto, não faz deles elementos de uma "língua artificial", mas parte da língua natural em uso em contextos específicos. Na seção seguinte apresentamos alguns modelos de classificação de topônimos, com ênfase para as taxionomias de Dick (1992), cujas taxes são entendidas aqui como termos da Toponímia e resultam em nosso objeto de estudo.

\section{Modelos de classificação de topônimos e taxionomias to- ponímicas: algumas considerações}

Em decorrência da necessidade de uma sistematização dos estudos toponímicos, surgiram modelos de classificação e taxionomias de topônimos elaborados por diferentes estudiosos do assunto e em diferentes fases da história da disciplina para recuperar a motivação da origem dos topônimos.

Não é demais lembrar que a Toponímia é uma disciplina vinculada às ciências do léxico - Lexicologia, Lexicografia e Terminologia - que tem exigido dos pesquisadores a formulação de modelos específicos de 
taxionomias para o estudo do topônimo. A essas taxionomias, dado o caráter terminológico de nossa pesquisa, denominamos de Terminologia taxionômico-toponímica (TTT). Assim, consideramos as taxionomias como termos da Toponímia.

Discutimos, neste tópico do trabalho, alguns modelos taxionômicos desenvolvidos por pesquisadores brasileiros e estrangeiros que "permitem interpretar os nomes de lugares com maior segurança do ponto de vista semântico" (DICK, 1999, p. 142). Entre eles, situam-se Albert Dauzat, Ivo Xavier Fernandes, José Leite de Vasconcellos, Everardo Backheuser, George Stewart, Maria Vicentina de Paula do Amaral Dick e SalazarQuijada.

Dauzat (1926, p. 23-33), por exemplo, incluiu os topônimos franceses em dois campos de influências - o da Geografia física e o da Geografia humana. Dick (1999, p. 140), ao tratar de questões terminológicas, esclarece que na proposta de Dauzat

as repartições no interior de cada um dos blocos referiamse a ocorrências ou a recortes espaciais identificados pelos paradigmas hidrográficos ou geomorfológicos (ex. Montblanc) e pelos empreendimentos antrópicos relativos à sedentarização do homem no terreno, à ocupação do solo, à construção das vilas e cidades, de acordo com as camadas étnicas constitutivas do povo francês (ex. Rochefort; Villeneuve).

Dauzat dividiu o mecanismo de nomeação em séries lógicas e em categorias históricas, estabelecendo um método de investigação toponímica. Assim, ao estudar os topônimos a partir desses dois ângulos, o pesquisador dá uma atenção especial às investigações, classificando-os segundo a ordem histórica de suas formações. Nesse sentido, focalizou a questão da denominação geográfica do ponto de vista da formação externa e dos sentidos intrínsecos ao nome. No que se refere à formação externa, $\mathrm{o}$ ato denominativo pode ser espontâneo - configurando-se como uma obra mais ou menos inconsciente do grupo, ou seja, aparentemente sem motivação - e também sistemático - quando resultante de atos refletidos de uma autoridade, de um fundador da cidade, de um proprietário. Já os sentidos intrínsecos englobam as denominações cujos nomes são emprestados da própria Geografia física, como no caso do córrego 
Buriti (MS) - referência às palmeiras com essa nomenclatura na região -, do rio Brilhante (MS) - característica da água límpida e cristalina do rio - ou de nomes de pessoas ilustres como fundadores ou proprietários, a exemplo do córrego Chico Borges (GO) - proprietário de fazenda próximo ao acidente geográfico -, ou, ainda, as que têm origem nos diversos caracteres abstratos ou de ordem histórica, como em córrego da Bandeira (GO).

Vasconcellos (1931, p. 139), por sua vez, ao estudar os nomes de lugares de Portugal, propôs uma classificação dos nomes geográficos divididos em três seções - nomes de lugar classificados por línguas, modos de formação toponímica e categorias de nomes segundo as causas que os originaram. As investigações de Vasconcellos referentes ao campo etnodialetológico dos nomes geográficos de Portugal levaram-no a concluir que a presença de várias línguas na toponímia local como a préromana, a romana, a germânica e a portuguesa, propriamente dita, pode ser explicada pelas fases de dominação da região pelos falantes dessas línguas e, por fim, pela formação e pela consolidação da própria língua materna, a portuguesa. Com relação ao modo de formação toponímica, as investigações estão relacionadas aos estudos gramaticais do sintagma nominativo. Já as categorias classificatórias dos nomes de lugares se relacionam às causas que lhes deram origem, como a flora, a fauna, a natureza do solo, a história, a religião.

Os estudos de Dauzat (1926) e de Vasconcellos (1931) enfatizaram que os nomes geográficos recuperavam características naturais do meio ambiente em que se encontravam inscritos, bem como os aspectos socioculturais presentes na designação geográfica, e postularam, também, a importância de estudos históricos e etimológicos do topônimo.

Xavier Fernandes (1941), em seu estudo Topônimos e gentílicos, nos apresenta um trabalho cujos topônimos são classificados conforme uma das "fontes toponímicas", como o autor mesmo ressalta, ou seja, de acordo com uma das diferentes subáreas da Onomatologia. Tais fontes são, pois, as diferentes "partes" da Onomatologia. Segundo o autor, a Toponímia como uma dessas partes, "tem por objeto o estudo dos nomes de lugares, terras ou regiões" (XAVIER FERNANDES, 1941, p. 9). Outros exemplos dessas áreas demonstradas pelo pesquisador são as seguintes:

Antropónimos são todos os nomes de homem ou mulher, incluindo-lhes, é claro, os apelidos e sobrenomes, com 
vida independente ou sem ela, como Júnior, sénior, etc. Astrónimos, são assim genericamente designados os nomes de astros em geral, sejam estrelas, planetas, cometas ou mesmo constelações Sol, Lua, Sírio, Cassiopeia, etc.). Axiónimos são todas as palavras ou locuções, com que se indicam tratamentos, dignidades com mais ou menos reverência, como Dom, Doutor, São ou Santo, Senhor, Vossa Eminência, Vossa Excelência, Vossa Alteza, Reverendíssimo, Sereníssimo, etc., vendo-se, por estes dois últimos e por outros idênticos, que também são considerados axiónimos certos qualificativos de forma adjectiva. Bibliónimos são os nomes de livros de reputação universal, como Bíblia, Alcorão, Talmude, Lusíadas, Eneida, Ilíada, Divina Comédia, etc. Cronónimos são os nomes de qualquer calendário, de eras históricas, de épocas, etc., como Janeiro, Hégira, Seiscentos (o mesmo que século XVII) e muitos outros. Etnónimos são os nomes de castas, raças, tribos ou povos e ainda os de comunidades tanto políticas como religiosas, desde que possam ser tomadas em sentido étnico (Brasileiros, Portugueses, Israelitas, Judeus, Tugues, etc.). Heortónimos são todos os nomes com que se designam festas populares e consagradas, como Carnaval, Lupercais, Bacanais, Olimpíadas, etc. Hierónimos são os nomes considerados sagrados em qualquer das religiões cristã, hebraica e maometana (Conceição, Natividade, Ressureição, JesusCristo, Jeová, Alá, etc.). Mitónimos são os nomes de seres fabulosos ou mitológicos, sejam designativos de entidades, de lugares ou de animais, como Minerva, Vénus, Baco, Marte, Cérbero, Deméter, Hades, etc. Potamónimos são os nomes de quaisquer rios, como Douro, Guadiana, Tejo, Amazonas, Pó, Zaire, etc. Prosónimos são os cognomes ou ápodos em geral (Africano, Conquistador, Lavrador, Sem-Pavor, etc.). Teónimos são os nomes de seres propriamente divinos, como Deus, Padre-Eterno, Santíssima-Trindade, etc. (XAVIER FERNANDES, 1941, p. 11-12, grifos do autor $)^{2}$.

${ }^{2}$ Sobre as diferentes partes da Onomatologia apresentadas por Xavier Fernandes (1954), cf. p. 13. 
Destacamos, nesse contexto, a análise que Xavier Fernandes faz sobre as fontes de toponímia como forma de apresentarmos uma visualização da classificação que o pesquisador fez dos nomes de lugares. Para o autor, "uma das fontes da Toponímia tem sido a Antroponímia" (XAVIER FERNANDES, 1941, p. 14). Tanto em Portugal como em outros países, são numerosíssimos os topônimos formados por nomes de pessoas e são também em grande número os nomes de pessoas usados como topônimos ${ }^{3}$.

Já Backheuser (1952) classificou os topônimos a partir de categorias gramaticais, como substantivo comum, substantivo abstrato e adjetivos, e de três figuras de retórica - a antonomásia, o pleonasmo e a metáfora - nas formações toponomásticas brasileiras.

$\mathrm{Na}$ categoria "substantivo comum", o autor distingue os topônimos de acordo com critérios geográficos: "oriundos de acidentes de geografia física" e "topônimos oriundos de ocorrências de geografia humana". Já os substantivos próprios aparecem nas designações de lugares em duas situações, a saber: pelos nomes de pessoas e pela autolatria e oportunismo (Ibid., p. 186).

Já os adjetivos - descritivos, metafóricos e eruditos -, segundo o autor, são mais abundantes nos acidentes físicos, utilizados para caracterizálos em termos de tamanho, de forma e de cor (Ibid., p. 188-189).

\footnotetext{
${ }^{3}$ Vale ressaltar alguns dados apresentados pelo autor, a saber: "América, do nome de Américo Vespúcio, navegador florentino, que em fins do século XV explorou a costa de Venezuela.; Atónio Enes, na costa de Moçambique.; Artur-de-Paiva, nome dado ao posto administrativo de Cassinga, no distrito de hiíla, província de Angola.; Astrida, capital do Ruanda, a oriente do Congo belga, na antiga África Oriental Alemã, tirado do nome da rainha da Bélgica, Astrid, que foi esposa de Leopoldo III e que morreu em 29 de Agôsto de 1935, vítima dum desastre de automóvel, na Suíça.; Baltimore, tirado do nome de lord Baltimore, chefe duma colónia de católicos ingleses, que no século XVII fundou a cidade do mesmo nome, a oriente dos Estados-Unidos da América (há também a cidade de Baltimore ao sul da Irlanda).; Bolívia, república sul-americana, nome de Simão Bolivar, campeão da independência local, obtida em 1825.; Botalândia, nome que chegou a ser dado à antiga colónia alemã do sudoeste africano e que foi formado com o nome do general Botha, herói da guerra anglo-boer de 1899 a 1902" (XAVIER FERNANDES, 1941, p. 14). Justificamos a apresentação desses dados devido ao fato de, até onde conhecemos, não serem muitos os pesquisadores toponimistas que possuem o trabalho do autor.
} 
Ao tratar das figuras de retórica, o pesquisador assinala que a antonomásia corresponde a um nome comum tomado por nome próprio ou o contrário, como em Nilo (vale), Pará, Paraná, Parima (rio); o pleonasmo refere-se à presença de um nome como designativo que geralmente, em outra língua, tem o mesmo significado do acidente geográfico nomeado, por exemplo, o rio Me-kong, uma vez que Me-Kong significa "rio" (Ibid., 169-150).

Stewart (1954, p. 2-9), por seu turno, divulgou mecanismos da nomeação onomástica, divididos em nove especificações: "1) Descriptive names; 2) Possessive names; 3) Incident names; 4) Commemorative names; 5) Euphemistic names; 6) Manufactured names; 7) Shift names; 8) Folk etymologies; 9) Mistake names".

Dick (1999, p. 141), manifestando-se sobre a proposta de Stewart, esclarece que

\begin{abstract}
os nomes descritivos e os comemorativos devem ser vistos com atenção especial, porque constituem protótipos de atividades denominativas gerais ou comuns a diferentes povos. Descrever uma paisagem em seus aspectos imanentes, essenciais, duradouros ou aspectuais, bem como homenagear, através dos nomes, indivíduos públicos, políticos, governadores, monarcas, artistas, religiosos, pessoas da própria família, enfim, são procedimentos que estimulam, de um lado, padrões objetivos de conduta e, de outro, transportam ao plano anímico de interesses personalíssimos.
\end{abstract}

Dick (1999) lembra ainda que as demais categorias alcançam menor índice de uso quando aplicadas a uma macrotoponímia, e que, embora o modelo de Stewart tenha sido criado para atender as necessidades do contexto americano (toponímia de base inglesa), pode suprir, e com muita utilidade, as camadas indígenas daquele território.

Dick, ao contrário de Stewart, elabora um modelo taxionômico que cataloga o produto gerado, o topônimo, no nível sincrônico, deixando os mecanismos de nomeação e o levantamento histórico e diacrônico para o "estudo descritivo das taxes isoladamente consideradas" (Id., 1992, p. 26). A primeira versão desse modelo formulado por essa pesquisadora integra a sua tese de doutorado, defendida em 1980, na Universidade de São Paulo, e continha dezenove taxes que visavam a preencher supostas 
lacunas que a proposta de Stewart (1954) não havia contemplado (DICK, 1992, p. 25).

Esse modelo preliminar foi posteriormente ampliado para 27 taxionomias, 11 que se referem aos nomes que resgatam peculiaridade de natureza física,e 16 que contemplam os topônimos de natureza antropocultural. Ressaltamos que todos os modelos de classificação de toponímicos mencionados, assim como as taxionomias aqui citadas, são muito relevantes para os estudos toponímicos, no entanto, neste trabalho, optamos pelo estudo mais detalhado do modelo ampliado por Dick $^{4}$ e publicado em 1992, que julgamos melhor responder às necessidades do toponimista brasileiro.

Na Venezuela, Salazar-Quijada (1985, p. 21-29) também propõe um modelo taxionômico para classificação dos topônimos que levou em conta cinco aspectos para a elaboração de suas taxionomias: i) elementos (simples ou compostos); ii) extensão, tamanho do acidente (microtopônimos, mesotopônimos e macrotopônimos); iii) localização (terrestres ou extraterrestres); iv) aplicação (actinônimos, astinônimos, corônimos, insunônimos, hidrônimos, odônimos, orônimos, espeleônimos, selenônimos), ou seja, de acordo com o tipo de acidente; v) motivação (fisiotopônimos, zootopônimos, fitotopônimos, mineratopônimos, epotopônimos, hagiotopônimos, somatotopônimos, animotopônimos, cognotopônimos, pragmatopônimos, topotopônimos). Nota-se que o modelo taxionômico do autor também possui caráter de Terminologia, ao passo que pelo próprio termo se evidencia a motivação do topônimo classificado.

Dos estudiosos mencionados, somente os modelos de classificação de Dick e Salazar-Quijada possuem, de fato, características de terminologia, uma vez que os termos taxionômicos utilizados e/ou elaborados por esses estudiosos possuem um valor semântico e funcionaldescritivo que dá conta da motivação toponímica em questão.

Sobre os modelos classificatórios mencionados, Gonsalves (2004, p. 32-37), por sua vez, compara os estudos de Vasconcellos (1931), Dauzat (1926), Stewart (1954) e Dick (1992). A pesquisadora assinala que Dick enfatiza, como primeiro aspecto a ser considerado no estudo da Toponímia, o conteúdo semântico perceptível no topônimo e que, nessa perspectiva, a investigação do nome geográfico tem como ponto de partida o próprio nome que, segundo ela, pode ser motivado - ou seja,

\footnotetext{
${ }^{4}$ Discorreremos detalhadamente sobre as taxionomias de Dick na próxima seção deste artigo.
} 
no ato da denominação, o nome pode ter sofrido influência de aspectos extralinguísticos de ordem física ou de natureza antropocultural.

Com base na comparação entre os modelos de classificação do topônimo, Gonsalves acrescenta que Dick completa as tendências classificatórias que podem estar presentes na toponímia de uma região, pois enquanto Dauzat (1926) encontrou duas tendências, a mística e a realista, Dick (1992) evidenciou 27 e as dividiu em taxionomias de natureza física e de natureza antropocultural, como já foi explicitado anteriormente. Gonsalves destaca outro aspecto que difere a orientação de Dick (1992) da dos europeus e da do norte-americano no que se refere à perspectiva de pesquisa:

Nos estudos de Leite de Vasconcellos (1931) e de Dauzat (1928), a perspectiva da pesquisa é voltada para o nível diacrônico do nome. Para Stewart (1954), é a história do nome que irá determinar o enquadramento em um dos 09 (nove) mecanismos de nomeação proposto por ele. Já na proposta de Dick (1992), os estudos desenvolvem-se em um nível sincrônico dos fatos e a investigação diacrônica dos dados fica em segundo plano, isto é, no momento de passar ao estudo das taxes isoladamente consideradas (GONSALVES, 2004, p. 35).

Diante do exposto, comungamos do pensamento de Gonsalves (2004, p. 35) quando assinala que a investigação do topônimo, segundo a perspectiva de Dick, prevê ao pesquisador a realização de uma análise que não se volte apenas para os aspectos internos da língua e, também, quando na tentativa de explicar a realidade toponímica por meio de fatos históricos e sociais da área pesquisada, os resultados não fiquem restritos ao plano das microestruturas regionais.

Como se pode perceber, os diferentes modelos taxionômicos propostos por estudiosos da toponímia representam tentativas de construção de paradigmas para a classificação dos topônimos, segundo diferentes perspectivas e categorias. Ressaltamos especialmente as taxionomias de Dick, com as quais o pesquisador pode, ao analisar o nome do lugar e classificá-lo de acordo com uma das 27 taxionomias, identificar o possível motivo da designação conforme a realidade toponímica brasileira. Destacamos também que, no processo de análise do topônimo, o pesquisador precisa recorrer a aspectos linguísticos e extralinguísticos e a informações oriundas de outras ciências para alcançar uma classificação mais adequada. Com tal postura, as classificações costumam resultar coerentes e coesas. 
As taxionomias toponímicas, em decorrência do caráter genérico que lhes são prerrogativas, auxiliam muito o estudioso na descoberta, numa perspectiva sincrônica, de características e anseios do povo de uma comunidade. No entanto, embora as 27 taxes de Dick possibilitem classificar os topônimos de forma bem ampla, ainda há aqueles que carecem de uma taxionomia mais adequada ao valor semântico que lhes são intrínsecos, como os casos que discutiremos no próximo item deste texto. Ressaltamos ainda, em meio a essa realidade, que novas denominações surgem em diferentes ambientes e que nem sempre são classificadas, evidenciando, desse modo, a necessidade de novas taxes. Nesse contexto, um toponimista acaba por desvendar diferentes intenções designativas que, quando não são contempladas por uma das 27 taxionomias de Dick, são identificadas nos trabalhos toponímicos como "não classificado" (NC), a exemplo das pesquisas realizadas no âmbito dos diferentes projetos de atlas toponímicos existentes no Brasil. Na sequência, apresentamos uma reflexão sobre as taxionomias de Dick (1992), com foco nos axiotopônimos e nos hierotopônimos, para justificar a taxionomia toponímica que propomos no presente texto.

\section{As taxionomias de Dick (1992): reflexões e proposta}

Neste item, discorremos sobre as taxionomias de Dick (1992) e apresentamos uma proposta de taxe com base em alguns problemas de classificação taxionômica evidenciados em nossas pesquisas toponímicas.

Em uma terminologia, em face dos aspectos funcionais, formais e semânticos de uma unidade terminológica, de acordo com a TCT, um termo é visto como unidade de conhecimento de determinada área e, também, como unidade pragmático-linguística. Logo, o termo pode ser estudado tanto na vertente conceitual, expressando conhecimentos e fundamentos dos saberes, quanto numa face linguística, determinando sua naturalidade e integração aos sistemas linguísticos, além dos aspectos que se agregam a suas funcionalidades comunicacionais básicas que, de acordo com Krieger e Finatto (2004, p. 80), "tem a função de fixar e favorecer a transferência do conhecimento".

A Terminologia Taxionômico-toponímica (TTT) aqui analisada cumpre com todos esses aspectos, pois cada uma das taxionomias possui uma funcionalidade sígnica que permite ao estudioso, a partir de sua 
forma e/ou estrutura linguística, dar conta da motivação da denominação numa perspectiva sincrônica.

Sua estrutura consiste na "adoção de um prefixo nuclear (grecolatino), de característica nocional, relativo a um dos dois campos de ordenamento cósmico, o físico e o humano, com acréscimo do termo 'topônimo', para dar a justa medida do campo de atuação da unidade onomástica criada" (DICK, 1999, p. 142).

Assim, hidro corresponde ao prefixo nuclear que caracteriza o nome do lugar (topônimo), formando a taxe hidrotopônimo - topônimos originados de nomes de acidentes geográficos que fazem referência ao elemento água, como em córrego do $A c ̧ u d e(\mathrm{GO})$. Quando o topônimo, em seu elemento específico, é composto por dois ou mais elementos lexicais, o modelo toma como base, para fins de classificação, o primeiro elemento da estrutura. Desse modo, em córrego Barreiro Grande (GO), considerase o formante Barreiro, atribuindo-lhe a classificação de litotopônimo, enquanto em córrego Buriti Comprido (GO), toma-se como referência a forma Buriti para classificá-lo como um fitotopônimo, formando a taxe para nomes de lugares cuja motivação foi um tipo de vegetal.

Observa-se que a própria TTT consegue, pela análise sêmica do signo toponímico, apresentar a motivação do nome do lugar, numa perspectiva sincrônica, como já mencionado. Destacamos também que as TTT se enquadram na categoria gramatical dos substantivos e são UTs simples por possuírem estruturas formadas por somente uma palavra.

Vejamos o modelo taxionômico elaborado por Dick (1992), aqui denominado por nós de TTT, no âmbito dos estudos da relação entre Toponímia e Terminologia, e conforme excerto da estrutura conceitual básica que elaboramos a partir das taxionomias da pesquisadora, disposta no organograma na Figura 1.

Para efeito de exemplificação das taxionomias, utilizamos os topônimos do corpus de Pereira (2009). Quando isso não foi possível, recorremos aos exemplos de Dick (1992, p. 31-34). Queremos ressaltar que as taxionomias toponímicas se caracterizam, em nosso entendimento, como termos da Toponímia, de forma que o nome de lugar - o topônimo propriamente dito - que se dá aos acidentes físico-geográficos e humanos é um nome próprio da língua geral, e não um termo. Ou seja, em córrego Buriti (GO), a denominação Buriti é o topônimo e a classificação taxionômica fitotopônimo é um termo da Toponímia. 


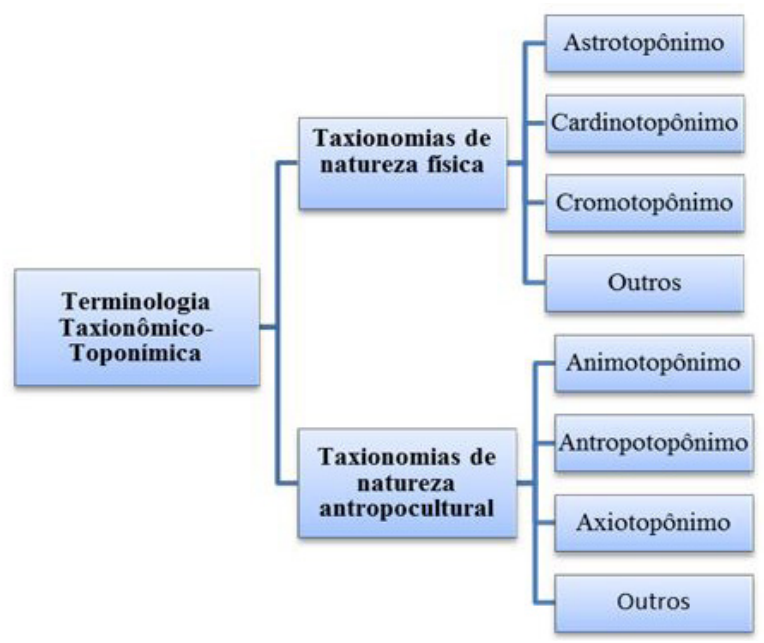

Figura 1 - Proposta básica de estrutura conceitual das taxionomias de Dick (1992) Fonte: elaborado pelos autores

\section{a) Taxionomias de natureza física}

1. Astrotopônimos: topônimos que se referem aos corpos celestes: rio da Estrela - $\mathrm{AH}^{5} /$ Espírito Santo.

2. Cardinotopônimos: topônimos referentes às posições geográficas: córrego da Divisa - AF/Itarumã (GO).

3. Cromotopônimos: topônimos relativos à escala cromática: serra $A z u l-\mathrm{AF} / \mathrm{Itarumã} \mathrm{(GO).}$

4. Dimensiotopônimos: topônimos referentes às características dimensionais dos acidentes geográficos, como extensão, comprimento, largura, espessura, altura, profundidade: morro Praião-AF/ Caçu (GO).

5. Fitotopônimos: topônimos originados de nomes de vegetais: serra da Guariroba - AF/Caçu (GO).

6. Geomorfotopônimos: topônimos referentes às formas topográficas, elevações ou depressões do terreno: córrego Furninha $\mathrm{AF} / \mathrm{Caçu}(\mathrm{GO})$.

${ }^{5}$ Acidente Humano.

${ }^{6}$ Acidente Físico. 
7. Hidrotopônimos: topônimos originados de acidentes hidrográficos: córrego do Açude - AF/Caçu (GO).

8. Litotopônimos: topônimos originados de nomes de minerais e de nomes relativos à constituição do solo: ribeirão Areia - $\mathrm{AF} / \mathrm{Caçu}(\mathrm{GO})$.

9. Meteorotopônimos: topônimos relativos a fenômenos atmosféricos: serra do Vento - AF/Paraíba.

10. Morfotopônimos: topônimos que refletem o sentido de forma geométrica: córrego Volta Grande - AH/Itarumã (GO).

11. Zootopônimos: topônimos de índole animal: córrego das Éguas - AF/Quirinópolis (GO).

b) Taxionomias de natureza antropocultural

1. Animotopônimos ou Nootopônimos: topônimos relativos à vida psíquica e à cultura espiritual: córrego Boa Vista-AF/Quirinópolis (GO).

2. Antropotopônimos: topônimos relativos aos nomes próprios individuais: córrego Manuel José - AF/Caçu (GO).

3. Axiotopônimos: topônimos que se referem a títulos e a dignidades que acompanham os nomes próprios individuais: córrego do Barão - AF/Gouvelândia (GO).

4. Corotopônimos: topônimos relativos aos nomes de cidades, países, estados, regiões e continentes: córrego Europa-AH/Acre.

5. Cronotopônimos: topônimos que encerram indicadores cronológicos como novo/nova, velho/velha: córrego Nova Descoberta - AF/Gouverlândia (GO).

6. Ecotopônimos: topônimos que fazem referência às habitações de um modo geral: córrego Taperão - AF/Caçu (GO).

7. Ergotopônimos: topônimos relacionados aos elementos da cultura material: córrego do Relógio - AF/Cachoeira Alta (GO).

8. Etnotopônimos: topônimos relativos aos elementos étnicos: córrego Caiapó - AF/Caçu (GO).

9. Dirrematotopônimos: topônimos construídos por meio de frases ou enunciados linguísticos: cidade ou bairro Valha-me Deus - $\mathrm{AH} /$ Maranhão.

10. Hierotopônimos: topônimos referentes aos nomes sagrados, às efemeridades religiosas, aos locais de culto: serra, córrego Cristo Rei - AF/Paraná. Podem apresentar duas subdivisões: a) hagiotopônimos: topônimos que se referem aos santos e às santas do hagiológio romano: 
córrego São Jerônimo - AF/Caçu (GO); b) mitotopônimos: topônimos referentes às entidades mitológicas: ribeirão do $\mathrm{Saci}-\mathrm{AH} / \mathrm{ES}$.

11. Historiotopônimos: topônimos que se referem a movimentos de cunho histórico-social, aos seus membros ou ainda às datas correspondentes: rio 7 de Setembro - AF/MT.

12. Hodotopônimos: topônimos relacionados às vias de comunicação: córrego da Ponte - AF/Caçu (GO).

13. Numerotopônimos: topônimos que dizem respeito aos adjetivos numerais: córrego das Três Barras - AF/Cachoeira Alta (GO).

14. Poliotopônimos: topônimos constituídos pelos vocábulos vila, aldeia, cidade, povoação, arraial: córrego do Arraial - AF/Itajá (GO).

15. Sociotopônimos: topônimos relacionados às atividades profissionais, aos locais de trabalho e aos pontos de encontro dos membros de uma comunidade: córrego do Retiro - AF/Caçu (GO).

16. Somatotopônimos: topônimos com relação metafórica às partes do corpo humano ou do animal: córrego Bocarra AH/Itajá (GO).

Importa assinalar ainda a subdivisão para a categoria dos animotopônimos proposta por Isquerdo (1996, p. 118) ao aplicar o modelo de Dick para o estudo da toponímia dos seringais e colocações do estado do Acre. A pesquisadora, fundamentando-se em duas "marcas" recorrentes nos topônimos dos seringais acreanos - impressão agradável/otimista e impressão desagradável/temeridade perante o referente nomeado -, propõe duas subcategorias para os animotopônimos, acrescendo-lhe os elementos eufórico e disfórico. Os animotopônimos eufóricos são representados por lexias que transmitem sensação agradável, expectativas otimistas (Alegria, Castelo, Encontro, Esperança, Liberdade, União etc.), enquanto os animotopônimos disfóricos recuperam lexias que transmitem sensação desagradável, expectativas não muito otimistas (Apertado, Cachorra Magra, Confusão, Chora Menino, Encrenca etc).

Como já mencionamos anteriormente, as taxes de Dick (1992) foram elaboradas com a intenção de facilitar o processo de descoberta da motivação dos topônimos. Entretanto, as características sociolinguísticoculturais de um país como o Brasil evidenciam necessidades de novas designações diariamente. Por isso, novos topônimos surgem na sociedade e, ao pesquisador, cabe a tarefa de estudá-los e demonstrar também para a sociedade a importância dessa designação enquanto reflexo da comunidade linguística à qual pertence. 
Embora as taxes de Dick consigam dar conta da motivação de quase todos os topônimos, algumas nomeações não são classificadas de forma clara e objetiva, devido à diversidade de motivações e significados que elas possuem e, por consequência, pela falta de novas taxionomias que cubram algumas necessidades classificatórias. Na sequência, apresentamos algumas discussões sobre esse fato e, posteriormente, uma possível taxionomia toponímica para designações de parentesco que acompanham nomes de lugares.

\section{Por uma proposta de taxionomia toponímica}

No âmbito de alguns projetos de atlas toponímicos existentes hoje no Brasil, a exemplo do Atlas Toponímico de Mato Grosso do Sul (ATEMS), sob a coordenação da Profa. Dra. Aparecida Negri Isquerdo, várias pesquisas têm sido realizadas e, com isso, novas descobertas designativas tem pulado aos olhos dos pesquisadores, principalmente aquelas relacionadas a topônimos que não são classificados de acordo com nenhuma das 27 taxes proposta por Dick (1992). Em face dessa realidade, como já mencionado no item anterior, tem havido a necessidade de estudos voltados para a elaboração de propostas de novas taxes toponímicas que deem conta da motivação, numa perspectiva sincrônica, dos topônimos que ficam como não classificados. Com este texto, propomos apenas uma taxionomia, mas esperamos que sirva de reflexão para novas possibilidades.

Tomemos como exemplo o caso do topônimo Padre, que geralmente é classificado como axiotopônimo. Este termo serve para classificar nomes próprios de lugares acompanhados por títulos e a dignidades. Por títulos, entende-se qualquer denominação honorífica, designação ou qualificação, como em conde, coronel, cabo, sargento etc. (FERREIRA, 2004). Já dignidade, Ferreira define como cargo, antigo tratamento honorífico e, também, função, honraria, título ou cargo que confere ao indivíduo uma posição graduada, de autoridade, como em prefeito, deputado, entre outros. Ao classificarmos Almirante, Coronel, Marquês, por exemplo, como axiotopônimos, os classificamos de forma consciente e clara.

No entanto, se classificarmos os topônimos Padre José de Anchieta/Jardim (MS), Padre Manoel da Nóbrega/Jardim (MS) e Padre Nilo Sheridan/Nioaque (MS), como axiotopônimos, parece-nos não muito pertinente devido ao fato da unidade léxica Padre não se tratar de um 
título, e sim de um "estado de vida" (GOMES, 2014). De acordo com o Código de Direito Canônico da Igreja Católica, do Papa João Paulo II (WOJTYŁA, 1983), o sacerdócio é um estado vocacional sagrado e perpétuo, de forma que um padre, em seu livre arbítrio, pode deixar de exercer sua ordem, de ministrar os sacramentos, afastando-se da Igreja para constituir família, por exemplo, mas não deixa de ser padre.

Há toponimistas que entendem o topônimo Padre como designativo de profissão, o que levaria a classificação de sociotopônimo. Entretanto, não comungamos dessa posição classificatória, pois o sacerdócio, mais especificamente no âmbito da igreja católica, é um fenômeno caracterizado pela missão de servir a Deus e ao próximo de forma incondicional, abstendo-se, assim, de muitos aspectos do mundo extraigreja.

Sobre o assunto, Gomes $(2014$, p. 1) ressalta que

O sacerdócio vem através de gerações, aperfeiçoando métodos, estratégias e linguagem, numa ousada missão: atualizar a força do anúncio do Evangelho para os novos/ nossos tempos. Concluo afirmando que o padre no serviço à comunidade, nas dimensões social e espiritual, quer unicamente ser o rosto do seu Mestre-Jesus, que o vocacionou e inspirou a esta missão. A vocação sacerdotal é um dom precioso do Cristo Pastor ao coração da sua Igreja. Ela imita mais de perto e perpetuamente a forma de vida que o Filho de Deus assumiu ao entrar no mundo, para cumprir a vontade do Pai. E por Ele estendida aos discípulos que o seguiam.

Como se percebe, o topônimo Padre não se trata de título ou dignidade nem de uma profissão. Tanto que um padre pode, por exemplo, exercer a profissão de professor ou outra qualquer, desde que não interfira na sua missão primeira junto à igreja.

O nome de lugar Padre se enquadra, de fato, no campo semântico das autoridades religiosas em geral. Ainda que esse topônimo por vezes seja classificado como axiotopônimo, julgamos mais de acordo classificá-lo como hierotopônimo. Se buscarmos em Dick (1992, p. 33), encontramos a seguinte definição para hierotopônimo:

Topônimos relativos aos nomes sagrados de diferentes crenças: cristã, hebraica, maometana, etc. Ex.: Cristo Rei 
(AH PR); Jesus (rio GO); Alá (lago AM); Nossa Senhora da Glória (AH AM); às efemeridades religiosas: Natividade (AH GO); Natal (AH AC); às associações religiosas: Cruz de Malta (AH SC); aos locais de culto: igreja: serra da igreja (PR); capela: Capela (AH AL); Capelazinha (AH MG) (DICK, 1992, p. 33).

Antes dessa definição, Dick (1990, p. 310-311, grifos nossos) já havia explicado com mais exatidão essa taxionomia, quando esclareceu que se vinculam aos hierotopônimos os nomes sagrados de diferentes crenças, as "associações religiosas e de seus membros, locais de culto, além de datas ou efemeridades relativas a tais circunstâncias".

Assim, podemos concluir que os nomes de autoridades religiosas, de modo geral, podem ser classificados seguramente como hierotopônimos, conforme Dick (1990, 1992), pois são membros de associações religiosas, independentemente de qual seguimento pertençam. O topônimo Padre, por sua vez, se enquadra nessa taxionomia. Vale destacar as palavras de Dick (1990, p. 304, grifos nossos) ao discorrer sobre os topônimos de origem antroponímica, quando explica que "esta classe de formações, em que o nome próprio vem acrescido de respectivos títulos pessoais, figura na categoria dos axiotopônimos, onde não foram incluídas as dignidades eclesiásticas, mencionadas entre os hierotopônimos".

Ademais, sugerimos uma taxionomia para nomes de lugares que fazem referência a grau de parentesco. Essa proposta se justifica pelo fato de encontrarmos trabalhos em que topônimos como Irmão Brasil/ Bodoquena (MS), Tio/São Gabriel do Oeste (MS), Vó Chica/Nova Andradina (MS), Vovó Josepha/Nova Andradina (MS) e Tia Cida/Nova Andradina (MS), por exemplo, são classificados como axiotopônimos. Não julgamos pertinente essa classificação porque irmão, tio e vovó não são títulos e dignidades que são atribuídas a uma pessoa por convenção social. Também não podemos classificá-los como etnotopônimos, pois estes, por sua vez, remetem tão somente aos "elementos étnicos, isolados ou não (povos, tribos, castas). Ex.: Guarani (AH PE); ilha do Francês (RJ); rio Xavante (MT); Chavantes (AH SP); Árabe (arroio, RS)" (DICK, 1992, p. 33).

Em casos como o mencionado anteriormente, não havendo uma taxionomia que em sua estrutura e significado seja possível evidenciar o valor semântico genérico que lhe é característico para classificar um topônimo de acordo com sua motivação, o procedimento que tem sido 
tomado por diversas pesquisas toponímicas no Brasil, a exemplo dos estudos realizados no âmbito dos projetos Atlas Toponímico do Estado de Mato Grosso do Sul (ATEMS) e Atlas Toponímico de Minas Gerais (ATEMIG), é o de deixar o topônimo como não classificado, como já explicitamos. Nesse contexto de classificação taxionômica pertinente ou não e de possibilidades de novas taxionomias, que atendam às demandas emergentes no mundo em constantes transformações e influências em que vivemos, é que nos propusemos a elaborar uma taxe para nomes que fazem referência aos diferentes graus de parentesco.

Para sugerirmos uma taxionomia para designações de parentesco que acompanham os nomes próprios individuais, nos foi necessário realizar uma busca pelos prefixos e radicais gregos e latinos com a intenção de encontrar um elemento que desse conta do caráter genérico que uma taxionomia precisa possuir. Nessa busca, encontramos duas possibilidades: Frater, tris: denominação de origem latina que serve para designar irmão, parente (PORTO EDITORA, 2010, p. 196); Parens, entis: denominação latina para referências a pai, mãe, avô, antepassado, os pais (pai e mãe), os antepassados (PORTO EDITORA, 2010, p. 349). Entre as duas, optamos por esta última por abranger de forma genérica as designações toponímicas que servem para homenagear um ente querido de qualquer grau. Com essa postura, aproveitamos o genitivo latino parentis que, agregado a topônimo, formou a taxionomia parentistopônimo: designações de parentesco que acompanham os nomes próprios individuais ou, tão somente, topônimo cuja unidade léxica é um signo linguístico que lembra qualquer grau de parentesco.

Justificamos nossa proposta com as palavras de Dick (1999) ao afirmar que as taxionomias toponímicas

não são exaustivas em suas ocorrências e, sim, exemplificativas, podendo ser ampliadas em seus categoremas (fitotopônimos, ergotopônimos, somatotopônimos, etc.) à medida que novas estruturas vocabulares se constituam, respeitando sempre o modelo originário, assim descrito: adoção de um prefixo nuclear (greco-latino) de característica nocional, relativo a um dos dois campos de ordenamento cósmico, o físico e o humano; acréscimo do termo "topônimo" ao elemento 
prefixal, para dar a justa medida do campo de atuação da unidade onomástica criada (DICK, 1999, p. 142).

Como se depreende pelo excerto, novas possibilidades de taxionomias toponímicas podem e devem ser elaboradas, desde que sigam os critérios apresentados pela pesquisadora e, logicamente, de acordo com as reais necessidades percebidas por meio dos estudos toponímicos.

\section{Considerações finais}

Com as discussões epistemológicas apresentadas nesse texto, verificamos que as taxionomias toponímicas, denominadas por nós de TTT, realizam-se como termos da Toponímia, pois correspondem a unidades léxicas pertencentes a essa ciência e que foram elaboradas em conformidade com as necessidades de Dick $(1990,1992)$, durante suas pesquisas, e que tem servido a todas as pesquisas toponímicas no Brasil, no âmbito de diferentes projetos de atlas toponímicos, a exemplo do ATEMS e do ATEMIG.

As TTT, em suas diferentes taxes, a exemplo dos antropotopônimos, fitotopônimos, zootopônimos, geomorfotopônimos etc., permitem classificações toponímicas dos nomes próprios de lugares, evidenciando a motivação numa perspectiva sincrônica. Ressaltamos que os nomes dos lugares não se constituem termos, e sim unidades léxicas da língua geral utilizadas para denominações de lugares. Assim, há de se fazer uma diferenciação clara entre termos da Toponímia e nomes próprios. Entendese por termos da Toponímia as TTT e, também, o nome topônimo que, por sua vez, é utilizado para referir ao nome próprio de lugar.

Com base em Cabré (1999), ressaltamos que as TTT possuem aspectos que a caracterizam como terminologia, ao passo que, pela estrutura linguística e valor semântico que cada taxe possui, é possível evidenciar a motivação dos topônimos de uma região numa perspectiva sincrônica. Tais características asseguram o valor funcional das taxionomias de Dick (1992), em especial no âmbito da TCT de Cabré (1999). Em decorrência disso, percebemos a funcionalidade que elas têm nos estudos toponímicos desenvolvidos no Brasil, ao contribuir com a sistematização e coerência dos pressupostos teórico-metodológicos seguidos pelos diferentes grupos de estudos existentes. 
Com esse trabalho de análise e proposta de taxionomia, esperamos que outros estudos sejam realizados para se somar a esse intento de contribuir com os estudos toponímicos já realizados ou em andamento.

\section{Referências}

BACKHEUSER, E. Toponímia: suas regras, sua evolução. Revista Geográfica, Rio de Janeiro, v. IX-X, n. 25, 1952, p. 163-195.

BARROS, L. A. Curso Básico de Terminologia. (Acadêmica; 54). São Paulo: Editora da Universidade de São Paulo, 2004

CABRÉ, M. T. La terminología: representación y comunicación. Elementos para una teoría de base comunicativa y otros artículos. Barcelona: Universitat Pompeu Fabra. 1999.

DAUZAT, A. Les noms de lieux: origine et évolution. Paris: Librairie Delagrave, 1926.

DICK, M V. P. A. A motivação toponímica e a realidade brasileira. São Paulo: Arquivo do Estado, 1990.

. Toponímia e antroponímia no Brasil. Coletânea de Estudos. São Paulo: USP, 1992.

. Método e questões terminológicas na Onomástica. Estudo de caso: a Toponímia do estado de São Paulo. Investigações - Lingüística e Teoria Literária, São Paulo, v. 9, p. 119-148, 1999.

FERREIRA, A. B. H. Novo Aurélio eletrônico versão 5.0: o dicionário de língua portuguesa - Século XXI. Curitiba: Positivo, 2004.

GOMES, P. C. Profissão: Padre? Irmãs Franciscanas Alcantarinas Província Nossa Senhora Aparecida. Artigos. Disponível em: <http:// www.franciscanasalcantarinas.org.br/artigos/Artigos\%20postados/ artigos6.htm>. Acesso em: 7 março de 2014.

GONSALVES, Doraci da Luz. Um estudo da toponímia da porção Sudoeste de Mato Grosso do Sul: acidentes físicos e humanos. (Dissertação Mestrado). Universidade Federal de Mato Grosso do Sul, Três Lagoas, 2004.

ISQUERDO, A. N. O fato lingüístico como recorte da realidade sóciocultural. 1996. Tese (Doutorado em Linguística e Língua Portuguesa) Universidade Estadual Paulista "Júlio de Mesquita Filho", Araraquara, 1996. 
KRIEGER, M. G.; FINATTO, M. J. B. Introdução à terminologia: teoria e prática. São Paulo: Contexto, 2001.

PEREIRA, R. R. A Toponímia de Goiás: em busca da descrição de nomes de lugares de municípios do Sul Goiano. Dissertação (Mestrado em Estudos da Linguagem) - Universidade Federal do Mato Grosso do Sul, Campo Grande, 2009.

PORTO EDITORA. Dicionário de Latim-Português/Português-Latim. Dicionários acadêmicos. Portugal: Porto Editora, 2010.

SALAZAR-QUIJADA, A. La Toponímia en Venezuela. Caracas: Universidad Central de Venezuela, 1985.

SILVA, O. L. Das ciências do léxico ao léxico nas ciências: uma proposta de dicionário português-espanhol de Economia Monetária. Tese (Doutorado em Linguística e Língua Portuguesa) - Faculdade de Ciências e Letras, Universidade Estadual Paulista "Júlio de Mesquita Filho", Araraquara, 2008.

STEWART, G. R. A classification of place names. Names, Beckerley, v. II, n. 1, p. 1-13, mar. 1954.

VASCONCELLOS, J. L. Opúsculos: Onomatologia, vol. III. Coimbra: Imprensa da Universidade, 1931.

WOJTYŁA, K. J. Código de Direito Canônico. 4. ed. Versão portuguesa de Antônio Leite. Lisboa: Conferência Episcopal Portuguesa, 1983.

WÜSTER, E. Internationale Sprachnormung in der Technik, besonders in der Elektrotechnik. Berlin: VDI Verlag, 1931.

XAVIER FERNANDES, I. Topónimos e gentílicos. Porto: Educação Nacional, 1941. 